\title{
What drives mortgage fees in Australia?
}

\author{
Benjamin Liu*, Eduardo Roca \\ Department of Accounting, Finance and Economics, Griffith University, \\ Brisbane, QLD, Australia
}

\begin{abstract}
We investigate the factors that affect total, ongoing and origination fees of mortgages in Australia during the period 1996 to 2011. We find that banks charge significantly higher total and ongoing fees than mortgage corporations although they require lower origination fees. We also find that fee levels are dependent on loan size, loan-to-value ratio, and loan features like term of the loan and presence of an offset account. Further, we confirm that lenders trade-off higher (lower) interest rates with lower (higher) fee levels. Finally, our results show that mortgage fees are significantly affected by market conditions.
\end{abstract}

Key words: Mortgage fees; Fee differentials; Mortgage lenders; Credit criteria JEF classification: G21, G30

The data collection is funded by a research grant from the Accounting and Finance Association of Australia and New Zealand and from Griffith University respectively. We would like to thank AFAANZ and Griffith University for providing the grants to support our research. 


\section{Introduction}

In most developed countries, housing property is the biggest household asset, and since this is acquired through borrowings, mortgages have become the biggest household debt. This situation has led to a very close linkage between the capital (mortgage) market and the housing market. The recent U.S. subprime crisis and the consequent global financial crisis (GFC) provide very compelling evidence of this close interaction between the housing and capital markets. Mortgage finance, therefore, plays an important role in the capital market and in the economy as a whole. In the case of Australia, as of year ending December 2011, the amount of outstanding mortgages stood at AU\$1.2 trillion dollars. However, in spite of its importance, empirical research on mortgage fees is very rare. This dearth in the literature motivated the authors to conduct this empirical study on Australian mortgage fees. As far as we know, this paper is the first study on Australian mortgage fees, as well as the first to test the different factors that affect the following three categories of mortgage fees - total fees, ongoing service fees and origination fees.

In addition to interest costs, origination and ongoing service fees are commonly paid by borrowers as extra mortgage costs. Fee income has become an important element for Australian banks. For example, in 2011 alone, fee income for banks reached $\$ 11.1$ billion $^{1}$. Indeed, when comparing mortgage fees across Australia, Canada, New Zealand, the U.K. and the U.S., Martin (2004) and the Australian Securities and Investment

\footnotetext{
${ }^{1}$ This is based on RBA's recent survey on banking fees at http://www.rba.gov.au/publications/bulletin/2011/jun/4.html
} 
Commission (2008) document that Australian lenders charge the highest fees among the surveyed countries.

The existing literature relating to mortgage fees concentrates on the U.S. market, where three government-sponsored enterprises dominate the secondary mortgage market (see Daniel, 2010 for an extensive discussion). In the literature, mortgage fees are studied in conjunction with securitisation costs and therefore, it is difficult for researchers to distinguish the impact of fees on mortgage costs from that of securitisation (e.g., Ambrose, LaCour-Little and Sanders, 2004). Most of the research on private label and asset-backed transactions ${ }^{2}$ suggests that securitisation can reduce costs and improve mortgage marketability. U.S. based research on mortgage fees also provides evidence on borrower mobility and the trade-off in the relationship between interest rates and fees (e.g., Brueckner, 1994).

This paper therefore aims to address the gap in the literature regarding the factors that affect the level of mortgage fees in Australia. Specifically, it seeks to provide answers to the following six major questions: (1) Are there fee differentials in total fees, ongoing service fees and origination fees across the two types of mortgage lenders - that is, banks and mortgage corporations? (2) Do differences in lender credit criteria impact on fee levels? (3) Do market conditions such as the GFC and the change of mortgage market liquidity also affect fees? (4) Does the trade-off relationship between interest rates and total mortgage fees in adjustable rate mortgages (ARMS) exist? (5) Does market competition affect the fees? (6) Are fees related to loan features?

\footnotetext{
${ }^{2}$ Private label mortgage securitisation is known as a non-agency transaction. Asset backed securitisation, known as ABS, involves securitising other categories of assets (e.g., credit card loans, auto loans and receivables). Securitisation is entirely a private sector market in Australia.
} 
In pursuit of the above objectives, we run multivariate regression models based on monthly standard mortgage rates and fee data of commercial banks and mortgage corporations, which consist of 4,616 observations pertaining to the periods (a) December 1996 to December 2006, and (b) December 2011. Data after December 2001 are hand collected as Australian mortgage data in standard databases were not publically available for that period.

The two groups of lenders that we examine in this paper are very different in terms of the way they fund their mortgages. Mortgage corporations securitise all the mortgages they originate while depository institutions (commercial banks) only do so for less than 10 percent of their mortgage lending. Note that mortgage corporations also differ from mortgage brokers. The former sell their own products to borrowers while the latter sell other companies' or banks' products. Our results can therefore offer further insight into the relationship between fee policies and credit criteria, loan features and other key factors such as the GFC and market competition in relation to each group of lenders. The literature clearly shows that the GFC greatly impacted on international banking systems and on the economy as a whole (see Lo, 2012; Mishkin, 2011); hence, we consider the GFC's effect on fees. We also take into account the impact of market competition on fees as the banking literature (Berger and Hannan, 1989; Liu and Skully, 2008) suggests that there is a positive relationship between the level of market concentration and the level of interest rates or yield spreads. Specifically, Ambrose and Conklin (2013) document that market competition in the U.S. leads mortgage brokers to reduce fee charges significantly. As we examine mortgage corporations rather than mortgage brokers, this paper differs from that of Ambrose and Conklin (2013). 
This paper contributes to the literature in the following ways. Firstly, it helps to close the information asymmetry gap between lenders and borrowers by providing a clearer picture of the mortgage fees charged by lenders. Woodward and Hall (2010) state that "the information asymmetry in this [mortgage] market is profound: borrowers engage in this transaction only a few times in their lives, while mortgage originators are experienced professionals who are well informed about prevailing prices and facile with the numbers and vocabulary" (p. 551). Secondly, as far as we know, our paper is the first to examine mortgage fee differentials and structures across lenders, as well as being the first to investigate the way in which credit criteria impacts on total fees, ongoing fees and origination fees. Finally, it also is the first examination into the way in which the GFC, market liquidity and market competition affect the mortgage fees.

Our findings suggest that banks charge significantly higher mortgage fees than nonbank lenders, although banks have lower origination fees. We also find, as expected, that the level of mortgage fees set by both banks and non-banks are significantly affected by their lending criteria - the larger the amount of loan granted, the higher the total mortgage fees. Our findings also show that lenders charge higher (lower) interest rates in exchange for lower (higher) fees. Finally, our results reveal that the change in market conditions arising from the GFC had a significant impact on the level of mortgage fees of both types of lenders. The GFC and the associated lower market liquidity resulted in lenders charging higher total fees. During the GFC, lenders offered lower origination fees; however, this was offset by much higher ongoing fees and thereby borrowers ended up paying higher total mortgage fees. 
The rest of this paper is structured as follows. Section 2 reviews the relevant literature relating to the possible factors that may affect mortgage fees. Section 3 describes the data, defines the variables used in the regression models and presents the regression models. Section 4 discusses the results of the empirical tests. Section 5 draws conclusions.

\section{Literature Review}

We review the literature as regards how each of the following affects mortgage fees: type of lenders - that is, bank or non-bank, lender credit criteria, potential trade-off between mortgage fees and interest rates, market conditions, market competition and loan features.

As regards the type of lender, a number of researchers have used lender data to investigate the effects of securitisation on originator pricing behaviour (e.g., Ambrose et al., 2004). They consistently found that mortgage firms which securitise all their loans offer lower mortgage rates or spreads than depository institutions which retain a major portion of their loans on their balance sheets. We therefore expect that banks will charge higher mortgage fees than mortgage corporations.

In relation to lending criteria, its effect on fee charges is seldom addressed in the literature. There are, however, a few papers which examine the impact of loan-to-value (LTV) ratios and loan size on mortgage yield spreads (e.g., Ambrose et al., 2004; Liu and Skully, 2005; Woodward and Hall, 2010). It is reasonable to expect that total fees, ongoing fees and origination fees charged by lenders may be used in a similar way as interest rates in response to lender credit policies (Todd, 2001). As larger loans and 
higher LTVs are perceived to have higher credit risk, it is therefore expected that these will be charged higher fees.

With regards to origination fees, in studies which focus on the U.S. market, these fees are considered as points or prepaid interest (Newmark et al., 2008) which can be used by lenders to address various types of risks (e.g., Kau and Keenan, 1987; Martin and Smyth, 1992). Thus, lenders may offer a trade-off between points and interest rates - borrowers can pay more points in exchange for a lower fixed interest rate, which has been documented both theoretically and empirically by studies (Stone and Zissu, 1990; Martin and Smyth, 1992; Brueckner, 1994). However, it is still unknown whether such a relationship between mortgage fees and interest rates also exists in Australia. We therefore empirically test this in this paper.

In relation to market conditions, research (e.g., Black et al., 1981; Liu and Skully, 2005 and 2008; Liu, Li and Roca, 2008) suggest that market liquidity significantly affects mortgage yield spreads. Therefore, a negative relationship between mortgage fees and market liquidity is expected. Moreover, the literature documents that the GFC greatly affected international banking systems and the economy as a whole (Lo, 2012; Mishkin, 2011) so that the increase in mortgage fees after the GFC is expected.

With regards to market competition, studies, based on either the markup theory (Rousseas, 1985) or the structure-performance framework (Berger and Hannan, 1989; Ambrose and Conklin, 2013), find that lower market competition leads to a higher price in banking products. Therefore, we expect that the degree of competition would be positively related to mortgage fees. 
Finally, in relation to loan features, in line with McClatchey et al. (2008), we examine the relationship of total fees with such loan characteristics as contract life (loan term) and the presence of an offset account - a feature that allows loan interest payments to be charged against interest earned by an account thereby resulting in tax savings (on interest earnings) for the borrower. We expect a positive relationship between contract life and mortgage fees since there is a liquidity premium for longer term loans (Muth, 1962; Ambrose et al., 2004). It also is possible that over the longer term, lenders may face a higher probability of prepayment (Daniel, 2008). With regards to the presence of an offset account, our expectation is that this will result in higher mortgage fees as the lender may need additional fees to compensate for the additional services required to administer offset accounts. Furthermore, it is possible that borrowers who avail themselves of the offset account feature are those who require larger loans in order to maximize tax savings and hence, higher mortgage fees would be involved.

\section{Methodology}

In line with the objectives of this paper and based on the relevant literature, we test the effect on total, ongoing and origination fees of the following variables: lender type, credit criteria, interest rates, market conditions, market competition and loan features.

\subsection{Variable definition and measurement}

Table 1 provides a summary of the proxies used for the different variables in the study. Total fees (TFEE), ongoing service fees (ONGOFEE) and origination fees (ORIGFEE) 
are all inflation-adjusted to make their values comparable across the research period. The year ending December 1996 is utilised as the base year for the CPI. The type of lender (e.g., Ambrose et al., 2004; Liu and Skully, 2005) is proxided by the dummy variable LENDER which is assigned the value of 1 for commercial banks and 0 otherwise (i.e. mortgage corporations). Hence, effectively, LENDER proxies for the effect of banks on mortgage fees as compared to that of mortgage corporations.

\section{[INSERT TABLE 1 ABOUT HERE]}

As proxies for credit risk, we use loan size (maximum loan) which are also inflationadjusted and LTV ratios (maximum LTV). For loan size, following the literature (Liu and Skully, 2005), we divide maximum loans into four groups: (a) less than $\$ 500,000$ [MaxLoan50], (b) between $\$ 500,000$ and $\$ 1,000,000$ [MaxLoan100], (c) greater than $\$ 1,000,000$ [MaxLoan200] and (d) no maximum amount or unlimited loan [MaxNo]. With regards to maximum LTV ratios, we divide these into three groups: (a) below $85 \%$ [MaxLTV85], (b) between 85\% and 90\% [MaxLTV90], and (c) greater than 90\% [MaxLTV95]. As most lenders require borrowers to buy mortgage insurance [MISLTV] if the LTV exceeds 80 percent, this minimum LTV by which lenders require borrowers to buy mortgage insurance is also considered.

In addition, to capture recent market developments, we use the GFC, mortgage market liquidity and prepayment risk as proxies. The GFC is represented by a dummy variable that takes the value of 1 for the period after July 2007 and 0 otherwise. Mortgage market liquidity $[M K T B T Y]$ is measured by the annual growth rate of the overall mortgage 
securitisation (see Black et al., 1981). Prepayment risk [YLDCUV] is represented by the excess yields of 3-month T-notes over those of 10-year T-bonds (see Ambrose et al., 2004).

As a measure of the degree of market competition, we use the share [MSHARE] of each lender of the total mortgage market. This is measured by the percentage accounted for by each lender of the total home loan outstanding in the mortgage market.

We consider whether a key feature of the loan affects fee levels. One of these loan features is whether a loan has an offset facility (see Section 2). We represent this through a dummy variable called OFFSET, which assumes the value of 1 for a loan with an offset account and 0 otherwise. Another loan feature that we consider is the term of the loan (time to maturity or contract life of the loan) or TERM. We classify TERM into three categories - namely, 25 to 26 years, [TERM26], 27 to 28 years, [TERM27] and 29 to 30 years, [TERM30]. Nominal interest rate $[R A T E]$ is represented by standard adjustable interest rates charged by lenders.

\subsection{Empirical Models}

As previously stated, we test the effect on total fees of each of these variables - lender type, credit criteria, loan features, interest rates, market conditions and market competition (see Table 1). We also test the effect of this set of variables but with the inclusion of an additional variable -origination fees, on ongoing fees. Finally, the same set of variables but with the addition of ongoing fees, are also tested for their effects on origination fees. 
Due to multicollinearity problems, we are not able to run one regression for each type of fees. Based on the results of the multicollinearity test, Variance Inflation Factor $(V I F)$, we found two variables, market share (MSHARE) and type of lender (LENDER) to have high multicollinearity as they have a VIF of 184.64 and 187.10 , respectively, which are well above the cut-off of 5 (see Studemund, 2001), and a correlation of 0.99 . We therefore have to separate these two variables from each other and put them into two separate regressions in order to avoid spurious regression results. Thus, we run two regressions for each type of fees.

For total fees, the generic regression equation is given by Equation 1. As mentioned, due to high multicollinearity between the independent variables LENDER and MSHARE, we could not run Equation 1. Instead, we estimated the two regressions represented by Equations 1(a) and 1(b). Equation 1(a) is the version of Equation 1 that excludes the independent variable-LENDER while Equation 1(b) excludes MSHARE.

$$
\begin{aligned}
& \text { TFEES }_{i}=\alpha_{0}+\alpha_{1} \text { GFC }_{i}+\alpha_{2} \text { MaxLTV95 }_{i}+\alpha_{3} \text { MaxLTV90 }_{i}+\alpha_{4} \text { MaxLTV85 }_{i} \\
& +\alpha_{5} \text { MaxLoan200 }_{i}+\alpha_{6} \text { MaxLoan100 }_{i}+\alpha_{7} \text { MaxLoan50 }_{i}+\alpha_{8} \text { MaxNo }_{i} \\
& +\alpha_{9} \text { MISLTV }_{i}+\alpha_{10} \text { MKTBLTY }_{i}+\alpha_{11} \text { YLDCUV }_{i}+\alpha_{12} \text { OFFSET }_{i} \\
& +\alpha_{13}{\text { TERM } 26_{i}+\alpha_{14} \text { TERM } 28_{i}+\alpha_{15}{\text { TERM } 30_{i}}+\alpha_{16} \text { RATE }}_{i} \\
& +\alpha_{17} M_{S H A R E_{i}} \text { or } \alpha_{17} L E N D E R_{i}+e_{i} \\
& \text { TFEES }_{i}=\alpha_{0}+\alpha_{1} \text { GFC }_{i}+\alpha_{2} \text { MaxLTV95 }_{i}+\alpha_{3} \text { MaxLTV90 }_{i}+\alpha_{4} \text { MaxLTV85 }_{i} \\
& +\alpha_{5} \text { MaxLoan200 }_{i}+\alpha_{6} \text { MaxLoan100 }_{i}+\alpha_{7} \text { MaxLoan50 }_{i}+\alpha_{8} \text { MaxNo }_{i} \\
& +\alpha_{9} \text { MISLTV }_{i}+\alpha_{10} \text { MKTBLTY }_{i}+\alpha_{11} \text { YLDCUV }_{i}+\alpha_{12} \text { OFFSET }_{i}
\end{aligned}
$$

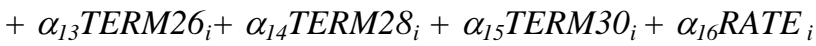

$$
\begin{aligned}
& +\alpha_{17} M S H A R E_{i}+e_{i} \\
& \text { TFEES }_{i}=\alpha_{0}+\alpha_{1} \text { GFC }_{i}+\alpha_{2} \text { MaxLTV95 }_{i}+\alpha_{3} \text { MaxLTV90 }_{i}+\alpha_{4} \text { MaxLTV85 }_{i} \\
& +\alpha_{5} \text { MaxLoan200 }_{i}+\alpha_{6} \text { MaxLoan100 }_{i}+\alpha_{7} \text { MaxLoan50 }_{i}+\alpha_{8} \text { MaxNo }_{i} \\
& +\alpha_{9} \text { MISLTV }_{i}+\alpha_{10} \text { MKTBLTY }_{i}+\alpha_{11} \text { YLDCUV }_{i}+\alpha_{12} \text { OFFSET }_{i}
\end{aligned}
$$

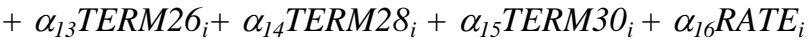

$$
\begin{aligned}
& +{ }_{I} \alpha_{17} L E N D E R+e_{i}
\end{aligned}
$$

This is the regression (Equations 1a and 1b). Table 1 defines each of the variables. 
For ongoing fees, the generic equation is provided by Equation 2 while the regressions that are estimated are given by Equations 2(a) and 2(b) which again separates the variables MSHARE and LENDER.

$$
\begin{aligned}
& \text { ONGOFEE }_{i}=\beta_{0}+\beta_{1} \text { GFC }_{i}+\beta_{2} \text { MaxLTV95 }_{i}+\beta_{3} \text { MaxLTV90 }_{i}+\beta_{4} \text { MaxLTV85 }_{i}
\end{aligned}
$$

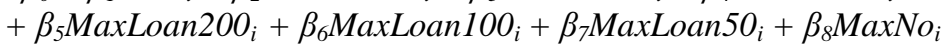

$$
\begin{aligned}
& +\beta_{9} \text { MISLTV }_{i}+\beta_{10} \text { MKTBLTY }_{i}+\beta_{11} \text { YLDCUV }_{i}+\beta_{12} \text { OFFSET }_{i}
\end{aligned}
$$

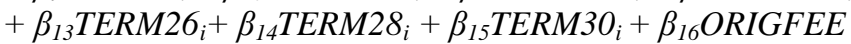

$$
\begin{aligned}
& +\beta_{17} \text { MSHARE }_{i} \text { or } \beta_{17} L E N D E R_{i}+e_{i} \\
& \text { ONGOFEE }_{i}=\beta_{0}+\beta_{1} \text { GFC }_{i}+\beta_{2} \text { MaxLTV95 }_{i}+\beta_{3} \text { MaxLTV90 }_{i}+\beta_{4} \text { MaxLTV85 }_{i}
\end{aligned}
$$

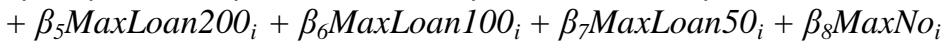

$$
\begin{aligned}
& +\beta_{9} \text { MISLTV }_{i}+\beta_{10} \text { MKTBLTY }_{i}+\beta_{11} Y_{L D C U V}+\beta_{12} \text { OFFSET }_{i}
\end{aligned}
$$

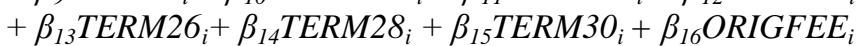

$$
\begin{aligned}
& +\beta_{17} \text { MSHARE }_{i}+e_{i} \\
& \text { ONGOFEE }_{i}=\beta_{0}+\beta_{1} \text { GFC }_{i}+\beta_{2} \text { MaxLTV95 }_{i}+\beta_{3} \text { MaxLTV90 }_{i}+\beta_{4} \text { MaxXLTV85 }_{i}
\end{aligned}
$$

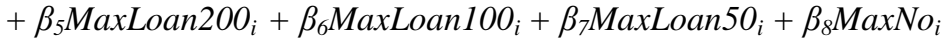

$$
\begin{aligned}
& +\beta_{9} \text { MISLTV }_{i}+\beta_{10} \text { MKTBLTY }_{i}+\beta_{11} \text { YLDCUV }_{i}+\beta_{12} \text { OFFSET }_{i}
\end{aligned}
$$

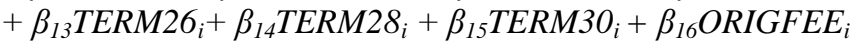

$$
\begin{aligned}
& +\beta_{17} L_{E N D E R_{i}+e_{i}}
\end{aligned}
$$

This is the regression (Equations $2 \mathrm{a}$ and $2 \mathrm{~b}$ ). Table 1 defines each of the variables.

Finally, the generic equation for origination fees is given by Equation 3 and the regressions which are estimated are Equations 3(a) and 3(b) which put MSHARE and LENDER in separate regressions.

$$
\begin{aligned}
& \text { ORIGFEE }_{i}=\lambda_{0}+\lambda_{1} \text { GFC }_{i}+\lambda_{2} \text { MaxLTV95 }_{i}+\lambda_{3} \text { MaxLTV90 }_{i}+\lambda_{4} \text { MaxLTV85 }_{i} \\
& +\lambda_{5} \text { MaxLoan200 }_{i}+\lambda_{6} \text { MaxLoan100 }_{i}+\lambda_{7} \text { MaxLoan50 }_{i}+\lambda_{8} \text { MaxNo }_{i} \\
& +\lambda_{9} \text { MISLTV }_{i}+\lambda_{10} \text { MKTBLTY }_{i}+\lambda_{11} \text { YLDCUV }_{i}+\lambda_{12} \text { OFFSET }_{i}
\end{aligned}
$$

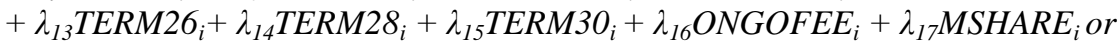

$$
\begin{aligned}
& +\lambda_{17} L_{E N D E R_{i}}+e_{i} \\
& \text { ORIGFEE }_{i}=\lambda_{0}+\lambda_{1} \text { GFC }_{i}+\lambda_{2} \text { MaxLTV95 }_{i}+\lambda_{3} \text { MaxLTV90 }_{i}+\lambda_{4} \text { MaxLTV85 }_{i} \\
& +\lambda_{5} \text { MaxLoan200 }_{i}+\lambda_{6} \text { MaxLoan100 }_{i}+\lambda_{7} \text { MaxLoan50 }_{i}+\lambda_{8} \text { MaxNo }_{i} \\
& +\lambda_{9} \text { MISLTV }_{i}+\lambda_{10} \text { MKTBLTY }_{i}+\lambda_{11} \text { YLDCUV }_{i}+\lambda_{12} \text { OFFSET }_{i}
\end{aligned}
$$

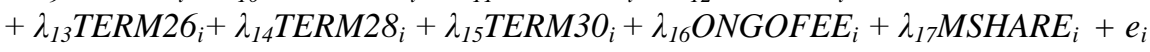

$$
\begin{aligned}
& \text { ORIGFEE }_{i}=\lambda_{0}+\lambda_{1} \text { GFC }_{i}+\lambda_{2} \text { MaxLTV95 }_{i}+\lambda_{3} \text { MaxLTV90 }_{i}+\lambda_{4} \text { MaxLTV85 }_{i} \\
& +\lambda_{5} \text { MaxLoan200 }_{i}+\lambda_{6} \text { MaxLoan100 }_{i}+\lambda_{7} \text { MaxLoan50 }_{i}+\lambda_{8} \text { MaxNo }_{i} \\
& +\lambda_{9} \text { MISLTV }_{i}+\lambda_{10} \text { MKTBLTY }_{i}+\lambda_{11} \text { YLDCUV }_{i}+\lambda_{12} \text { OFFSET }_{i}
\end{aligned}
$$

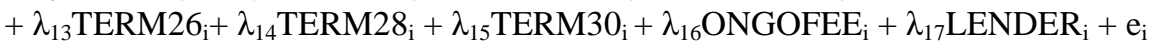


This is the regression (Equations $3 a$ and $3 b$ ). Table 1 defines each of the variables.

\subsection{Data}

The data consists of 6,850 observations of standard adjustable rate mortgages (ARMs) pertaining to the periods December 1996 to December 2006 and the year ending December 2011 and including almost all commercial banks and most mortgage corporations. After screening out the loans without loan terms, 4,616 observations remained. As of the year ending December 2011, based on statistics of the Reserve Bank of Australia, commercial banks and mortgage corporations have a combined market share of 96.1 percent of the mortgage market so these two groups sufficiently represent the Australian market. The data relating to the year 2011 allows us to examine the effect of recent market developments such as the GFC. For the period December 1996 to December 2001, mortgage data is gathered from Cannex's monthly survey of Australian lenders, while the data from January 2002 to December 2006, just before the GFC, are hand collected from home loan tables in Your Mortgage Magazine. The data for the year

ending December 2011 is hand collected from the website (http://www.infochoice.com.au). From these three sources, we obtained a comprehensive mortgage dataset - a total of 6,850 observations.

To make the data comparable across lenders, only standard ARM residential mortgages with 25-30 years maturity were used. The datasets include nominal interest rates, originators' fees, terms, maximum loans and maximum loan-to-value (LTV) ratios, as 
well as product features, such as an offset account. Other data pertaining to mortgage securitisation, yields of three-month Treasury notes and ten-year Treasury bonds, and 90day bank bills, outstanding home loans of each type of lenders (commercial banks, mortgage corporations, building societies and credit unions) and consumer price index are collected from the statistical databases of the Reserve Bank of Australia and the Australian Bureau of Statistics.

A limitation is that data does not cover the period from 2007 to 2010 and some months of 2011. This is primarily due to two reasons. The first has to do with data unavailability as the Your Mortgage Magazine ceased to exist in the midst of 2008. The second reason is that lenders are unidentifiable from 2007 , and thus we are unable to use information pertaining to lender type during that period. As mentioned earlier, the impact of recent market developments is also captured through the 2011 data that we collected.

\section{Results and Discussion}

\subsection{Total fee levels}

Table 2 presents the results of the two regressions (Equations $1 \mathrm{a}$ and $2 \mathrm{~b}$ ) in relation to total fees. In both regressions, lender type (LENDER) is found to be significantly related to total fees (with a $p$-value of 000 ). Recall that LENDER is represented by a dummy variable in which banks are assigned a value of 1 and mortgage corporations, a value of 0 . The coefficient of LENDER therefore represents the increase or decrease in total fees due to the lender type being a bank. In other words, this coefficient is the differential in fees 
between banks and mortgage corporations. The results presented in Table 2 show that the coefficient for $L E N D E R$ is 929 . This suggests therefore that banks require 929 dollars more in fees than mortgage corporations. Furthermore, in the post GFC period, as indicated by the coefficient of the variable $G F C$, lenders charge 800 dollars more in total fees than that in the pre GFC period (see Equation 1b).

As discussed in the Literature Review, we expect that a higher (lower) LTV is associated with a higher (lower) fee. Note that in Equations 1a and 1b, we control for maximum LTV with values above 90\% (MaxLTV95). Therefore, a positive (negative) coefficient for each of the other two categories which represent lower LTVs, i.e. LTVs below 85\% (MaxLTV85) and LTVs between 85\% and 90\% (MaxLTV90), implies that LTV and mortgage fees are negatively (positively) related. It can be seen in Table 2 that MaxLTV85 is negatively related to the fee level at a 1 percent level of significance. This finding therefore confirms that mortgage fees and LTV are positively related, which is consistent with prior research (Ambrose et al., 2002; Liu and Skully, 2005). However, the coefficient of MaxLTV90 is found to be positive, which means that there is a negative relationship between LTV and mortgage fees. This finding suggests that it is possible that lenders encourage borrowers to take loans with higher risk (LTV above 90\%) by charging lower fees as lenders normally require the borrowers to buy mortgage insurance if the LTV exceeds $80 \%$.

In the Literature Review we stated that loan size is generally expected to be positively related to mortgage fees. In Equations $1 \mathrm{a}$ and $1 \mathrm{~b}$, we control for no maximum loans (MaxNo) required by the lender in their policies. This implies that if this expectation is to be confirmed, there should be a negative coefficient for each of the three other categories 
of loan size because these loan sizes are smaller. The results show that the other two groups for maximum loans - MaxLoan100 and MaxLoan50, are negatively associated with total fees (TFEE) at a 1 percent level of significance, which therefore confirms our expectation of a positive relationship between loan size and mortgage fees.

More interestingly, from the estimation results for the two Equations, as shown in Table 2, we find that interest rates are negatively related to total fees at a 1 percent level of significance. This result is consistent with the prior U.S. research on the trade-off relationship between interest rates and fees (e.g., Stone and Zissu, 1990; Brueckner, 1994).

Furthermore, offset account (OFFSET), terms (TERM28 and TERM30) and market share $(M S H A R E)$ are all positively related to total fees at a 1 percent level of significance. Loans with the offset feature charge over 700 dollars more in fees than those without this feature. With regards to mortgage terms, the longer the term of the loan, the higher the fees lenders require. Loans with terms of 27- 28 years (TERM28) and 29-30 years (TERM30) are charged total fees, of 579 and 235 dollars, respectively, as indicated in Equation 1a, and 581and 240 dollars, respectively, as shown in Equation 1b, which are higher than fees for loans with 25-26 year term (TERM26). This finding is consistent with prior studies of yield spreads (see Section 2). Also, in both regression Equations 1a and $1 \mathrm{~b}$, it is found that market liquidity $(M K T B T Y)$ negatively impacts on total fees, as we predicted.

[INSERT TABLE 2 ABOUT HERE] 


\section{2. Ongoing service fees}

As mentioned, we examine the determinants of ongoing fees in Equations $2 \mathrm{a}$ and $2 \mathrm{~b}$. As shown in Table 3, in Equation $2 \mathrm{~b}$, the lender dummy (LENDER) is positively related to ongoing fees at the 1 percent level with a coefficient of 973 . This indicates that banks charge nearly 973 dollars more in ongoing fees than mortgage corporations. Again, in both Equations, the $G F C$ is found to positively affect ongoing service fees at a 1 percent level of significance. It can be seen in Equations $2 a$ and $2 b$ that lenders' fees have increased by around 1,000 dollars post GFC.

\section{[INSERT TABLE 3 ABOUT HERE]}

The relationships between ongoing fees and credit criteria (Equations 2a and 2b) are found to be consistent with those found in previous studies (e.g., Ambrose et al., 2004). In these equations, MaxLTV95 is controlled so that a positive (negative) coefficient for the lower LTVs - MaxLTV85 and MaxLTV80, would imply a negative (positive) relationship of LTVs with on-going fees. MaxLTV85 is found to have a negative coefficient at a 1 percent level. This is consistent with prior yield spreads studies (see Section 2) and our expectation. This suggests that lenders require lower ongoing fees for lower LTVs, as loans with lower LTVs are perceived to have lower default risk. In contrast, MaxLTV90 has a positive coefficient which implies that borrowers at this MaxLTV90 category pay higher ongoing fees than borrowers at the MaxLTV95 category. 
Borrowers in the category of MaxLTV90 are required to buy mortgage insurance which serves as an encouragement for them to take loans with higher risk (i.e. MaxLTV95).

Maximum loan amounts are regarded to be the same as maximum LTVs in lender credit policies (e.g., Ambrose et al, 2004) - that is, we expect a positive relationship between loan size and on-going fees. In Equations $2 \mathrm{a}$ and $2 \mathrm{~b}$, we control for no maximum-required loan (MaxNo). This means that if our expectation is to be confirmed, each of the other three groups (MaxLoan200, MaxLoan100 and MaxLoan50) representing lower loan sizes should have a negative coefficient. As shown in Table 3, this is the case which is consistent with the literature.

Surprisingly, the results for Equations $2 \mathrm{a}$ and $2 \mathrm{~b}$ show a positive relationship between ongoing fees and origination fees at the 1 percent level. This is inconsistent with prior research based on a two-period model or trade-off model (e.g., Brueckner, 1994). This implies that if a lender charges higher upfront fees it will also charge higher ongoing fees.

Moreover, offset account (OFFSET) is found to be significantly related to ongoing fees at a 1 percent level with a coefficient of about 700 . This indicates that lenders charge nearly 700 dollars more in ongoing fees for loans with an offset account than loans without this feature. In addition, contract maturities (terms) also turned out to be important determinants of fees. When TERM26 (25 to 26 years) is controlled, we find that TERM28 (27 to 28 years) and TERM30 (29 to 30 years) are positively related to ongoing fees at a 1 percent level of significance. This means that the longer the term of the loan, the higher the fees which are involved. This is consistent with prior research (e.g., Muth, 1962). Market share (MSHARE) is also positively related to total fees at a 1 percent level of significance. 
Again, as expected and consistent with the literature, market liquidity (MKTBTY) is negatively related to ongoing fees, as we predicted. Thus, the lower (higher) the market liquidity, the higher (lower) the ongoing fees.

\subsection{Origination fees}

As shown in Table 4, the results pertaining to origination fees present a different picture from those of ongoing fees. In Equations $3 \mathrm{a}$ and $3 \mathrm{~b}, L E N D E R$ is negatively related to origination fees at a 1 percent level (LENDER has a negative coefficient). This suggests that banks offer lower origination fees. Hence, it seems that they focus on ongoing fees rather than origination fees. They receive lower origination fees but charge higher ongoing fees. We also find that, in contrast to ongoing fees, origination fees have a negative relation to the variable $G F C$ at a 1 percent level. This implies that during tight market conditions, lenders lower their origination fees. Perhaps, lenders do so in an attempt to attract borrowers.

\section{[INSERT TABLE 4 ABOUT HERE]}

The results in Equations $3 \mathrm{a}$ and $3 \mathrm{~b}$ indicate some significant relationships between fees and the maximum LTV and the loan size. Again, we control for MaxLTV95 in these two regressions. Contrary to what we found with regards to ongoing fees, there is a positive coefficient for MaxLTV85 which means that lenders charge lower fees for riskier loans (i.e. MaxLTV95). Perhaps, lenders are willing to offer borrowers lower fees in order to encourage them to take higher risk loans which could then enable them to get 
higher fees at a later stage in terms of ongoing fees. With regards to maximum loans, when we control for MaxNo, only MaxLoan50 is significant (at a 1 percent level) with a negative coefficient. This implies that lower loan size results in lower origination fees. Thus, origination fees seem to be negatively related to the LTV but positively related to the loan size.

The offset account and TERM28 (where TERM26 is controlled) have a significant (1 percent level) positive relationship with origination fees. Hence, it appears that loans with features such as an offset account and also loans with longer terms are charged higher origination fees.

In Table 4, it can be seen that market share is significant (at a 1 percent level). A higher market share reduces origination fees but the magnitude of the reduction is relatively small, compared to the resulting increase in ongoing fees. This indicates that when lenders increase their market share, they slightly reduce their upfront fees, but this is far smaller than the increase in the fees they charge over the life of the loan. As a consequence, total fees increase (by over 1,200 dollars) (see Table 2). This slight reduction of the upfront fee is therefore something like "window dressing" for the purpose of attracting borrowers.

In Equations $3 \mathrm{a}$ and $3 \mathrm{~b}$, a significant association between market liquidity and origination fees is found at the 1 percent level. However, in contrast to total and ongoing fees, this relationship is a positive one. Again, this seems to indicate that in times of low market liquidity, lenders attempt to bring in borrowers by lowering their origination fees and then later on make up for this loss in fees by charging higher ongoing fees in such a way that lenders still end up paying higher fees overall. 


\section{Conclusion}

This paper investigates the key factors that may affect differences in total, ongoing service and origination fees of Australian mortgage lenders. Using a large dataset, we examine the degree to which there are fee differentials across two major types of lenders; whether differences in lender credit criteria and the loan feature impact on fee levels; and also whether there is a trade-off relationship between interest rates and mortgage fees. Further, we also investigated whether the GFC, market share and mortgage market liquidity affect fee levels.

Table 5 summarises our key findings corresponding to each of the six research questions posed in the Introduction. As expected, there were statistically significant differences in fee charges between commercial banks and mortgage corporations. Regression estimates suggest that banks require significantly higher total fees and ongoing fees than mortgage corporations. Our results confirm the negative relationship between total fees and nominal interest rates which means that lenders with higher interest rates tend to collect lower fees. This finding is consistent with the literature, as well as with our expectations.

\section{[INSERT TABLE 5 ABOUT HERE]}

As expected, fee levels (total and ongoing fees) are dependent on credit criteria. These fees are positively related to maximum LTVs and the amount of maximum loans. Similarly, ongoing fees behave something like yield spreads and therefore are also sensitive to lender credit criteria. All the three types of fees have a positive link to loan 
terms. This is consistent with the literature that deals with the relationship between interest rates or spreads and lender credit criteria (e.g., Ambrose et al., 2004; Liu and Skully, 2008; LaCour-Little, 2009). This paper extends the existing literature as it provides statistical evidence about the relationship between fees and credit criteria using unique data (most of which is hand collected).

More interestingly, we find that the change in market conditions as proxied by the GFC and market liquidity significantly affect fee levels. Collectively, these results are also consistent with discussions in the recent literature (e.g., Mishkin, 2011; Liu and Skully, 2008). Banks charge higher total mortgage fees which increase when market liquidity decreases. These higher total fees, however, come from ongoing fees, not from origination fees. In fact, origination fees for banks are lower during stressed market conditions, such as during the GFC. It seems, therefore, that during the GFC banks attempt to lure borrowers - through lower origination fees, and then subsequently increase ongoing fees, allowing them to earn higher total fees. Borrowers, however, have some flexibility to trade-off interest rates and total fees.

One of the contributions of this paper is that it is the first to investigate the impact of credit criteria on total fees, ongoing fees and origination fees, as well as the association between adjustable interest rates and total fees. It is also one of the first empirical examinations of mortgage lending, taking into consideration the recent market conditions in Australia. Further examination of these variables could be undertaken with additional data relating to the recent years to flesh out in greater depth the impact of recent market developments. 


\section{References}

Ambrose, B.W., and J. Conklin, 2013, Mortgage brokers, origination fees, price transparency and competition, Real Estate Economic 32 (forthcoming).

Ambrose, B.W., M. LaCour-Little, and A. B. Sanders, 2004, The effects of conforming loan status on mortgage yield spreads: a loan level analysis, Real Estate Economic 32, $541-569$.

Australian Securities and Investment Commission, (2008), Review of mortgage entry and exit fees, Report 125. Available at http://www.fido.gov.au/asic/pdflib.nsf/LookupByFileName/REP_125_Review_of_mo rtgage_entry_and_exit_fees.pdf/\$file/REP_125_Review_of_mortgage_entry_and_exit _fees.pdf

Black, D.G., K. D. Garbade, and W. L. Silber, 1981, The impact of the GNMA passthrough program on FHA mortgage costs, Journal of Finance 36, 457-469.

Berger, A. N., and T, Hannan, 1989, The price-concentration relationship in banking, Review of Economics and Statistics 7, 291-299.

Brueckner, J. K., 1994, Borrower mobility, adverse selection and mortgage points, Journal of Financial Intermediation 3, 416-441.

Daniel, J., 2010, A fixed-rate loan prepayment model for Australian mortgages, Australian Journal of Management 35, 99-112.

Kau, J. B., and D. C. Keenan, 1987, Taxes, points and rationality in the mortgage market, AREUEA 15, 68-184.

LaCour-Little, M., 2009, The pricing of mortgages by the brokers: An agency problem?, Journal of Real Estate Research 31, 235-333. 
Liu, B., and M. Skully, 2005, The determinants of mortgage yield spread differentials: Securitisation, Journal of Multinational Financial Management 15, 314-333.

Liu, B., and M. Skully, 2008, The impact of securitisation and structural changes of Australian mortgage markets on bank pricing behavior, International Journal of Banking, Finance and Accounting 1, 149-167.

Liu, B, Li, D and Roca, E, 2008, What determine mortgage yield spreads in Australia? Credit Criteria, funding channels and the market condition, Paper presented at 21st Australasian Banking and Finance Conference, Sydney.

Lo, A. W., 2012, Reading about the financial crisis: A 21-book review. Available at http://www.argentumlux.org/documents/JEL_6.pdf.

Martin, L. N. 2004, International mortgage cost comparisons, Fujitsu Australia, Sydney.

Martin, R. E., and D. J. Smyth, 1992, Points, risk and structure in the mortgage market, Southern Economic Journal 58, 779-789.

McClatchey, C., and C. de la Torre, 2008, Your mortgage loan: Fairly priced, ... or not?, Financial Services Review 17, 237-256.

Mishkin, F. S., 2011, Over the cliff: From the subprime to the global financial crisis, Journal of Economic Perspectives 25, 49-70.

Muth, R. F., 1962, Interest rates, contract terms and allocation of mortgage funds. Journal of Finance 17: 63-80.

Newmark, R., C. de la Torre, and M. A. Stallings, 2008, An after-tax analysis of negative mortgage points, Real Estate Taxation 35, 154-161.

Rousseas, S., 1985, A markup theory of bank loan rates, Journal of Post Keynesian Economics 8, 135-144. 
Stone, C. A., and A. M. Zissu, 1990, Choosing a discount point/contract rate combination, Journal of Real Estate Finance and Economics 3, 283-293.

Studenmund, A. H., 2001, Using econometrics: a practical guide (fourth ed.) (Addison Wesley Longman, Boston).

Todd, S., 2001, The effects of securitisation on consumer mortgage costs, Real Estate Economics 29, 29-54.

Woodward, S. E., and E. Hall, 2010, Consumer confusion in the mortgage market: Evidence of less than a perfectly transparent and competitive market, American Economic Review: Papers \& Proceedings 100, 511-515. 
Table 1

Definitions of mortgage fees, credit criteria and other factors

\begin{tabular}{|c|c|c|}
\hline Notation & Variable Name & Definition \\
\hline \multicolumn{3}{|l|}{ Mortgage Fee } \\
\hline TFEE & Total fees & $\begin{array}{l}\text { Inflation adjusted dollar amount of all types of } \\
\text { fees }\end{array}$ \\
\hline ONGOFEE & Ongoing service fees & Inflation adjusted dollar amount of ongoing fees \\
\hline ORIGFEE & Origination fees & $\begin{array}{l}\text { Inflation adjusted dollar amount of all types of } \\
\text { upfront fees }\end{array}$ \\
\hline \multicolumn{3}{|l|}{ Lender Type } \\
\hline LENDER & Lender type & $\begin{array}{l}\text { Dummy variable for lender type, banks as } 1 \text {, } \\
\text { otherwise (mortgage corporations) } 0\end{array}$ \\
\hline \multicolumn{3}{|l|}{$\begin{array}{l}\text { Credit Criteria } \\
\underline{L T V}\end{array}$} \\
\hline MaxLTV95 & $\begin{array}{l}\text { Maximum LTV as credit } \\
\text { risk }\end{array}$ & Maximum LTV > 90 percent \\
\hline MaxLTV90 & $\begin{array}{l}\text { Maximum LTV as credit } \\
\text { risk }\end{array}$ & 90 percent $=\langle$ maximum LTV $>=85$ percent \\
\hline MaxLTV85 & $\begin{array}{l}\text { Maximum LTV as credit } \\
\text { risk }\end{array}$ & Maximum LTV $<85$ percent \\
\hline MISLTV & Mortgage insurance LTV & $\begin{array}{l}\text { LTV at which the borrower needs to buy an } \\
\text { insurance }\end{array}$ \\
\hline \multicolumn{3}{|r|}{ 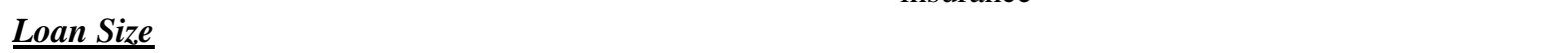 } \\
\hline MaxLoan200 & Maximum loan as credit risk & Maximum loans $>\$ 1,000,000$ \\
\hline MaxLoan100 & Maximum loan as credit risk & $\$ 1,000,000=<$ maximum loans $>=\$ 500,000$ \\
\hline MaxLoan50 & Maximum loan as credit risk & Maximum loans $<\$ 500,000$ \\
\hline MaxNo & Maximum loan as credit risk & $\begin{array}{l}\text { No Maximum loans required by the lender in } \\
\text { their policy }\end{array}$ \\
\hline \multicolumn{3}{|l|}{ Market Condition } \\
\hline$G F C$ & Global financial crisis & $\begin{array}{l}\text { Dummy variable for GFC as } 1 \text { after July } 2007 \text {, } \\
\text { otherwise } 0\end{array}$ \\
\hline MKTBTY & Market liquidity change & $\begin{array}{l}\text { Annual growth rate of overall mortgage } \\
\text { securitisation }\end{array}$ \\
\hline$Y L D C U V$ & Proxy of prepayment risk & $\begin{array}{l}\text { Yields of 3-month T-notes over those of } 10 \text { - } \\
\text { year T-bonds }\end{array}$ \\
\hline \multicolumn{3}{|c|}{ Market Competition } \\
\hline MSHARE & Market share & $\begin{array}{l}\text { Market share of banks and mortgage } \\
\text { corporations respectively }\end{array}$ \\
\hline \multicolumn{3}{|c|}{ Loan Feature and Term } \\
\hline OFFSET & Offset account with a loan & $\begin{array}{l}\text { Dummy for a product feature with a loan (offset } \\
\text { account) }\end{array}$ \\
\hline TERM26 & Term & Contract life from 25 to 26 years \\
\hline TERM 28 & Term & Contract life from 27 to 28 years \\
\hline TERM30 & Term & Contract life from 29 to 30 years \\
\hline \multicolumn{3}{|l|}{ Interest Rate } \\
\hline RATE & Nominal interest rate & Standard adjustable interest rates of lenders \\
\hline
\end{tabular}


Table 2

Regression estimate on total mortgage fees for all lenders

\begin{tabular}{|c|c|c|c|c|c|c|c|}
\hline \multirow[b]{2}{*}{ Variables } & \multirow{2}{*}{$\begin{array}{c}\text { Expect. } \\
\text { Sign }\end{array}$} & \multicolumn{3}{|c|}{ Equation 1a } & \multicolumn{3}{|c|}{ Equation $1 \mathrm{~b}$} \\
\hline & & Coeff. & $t$-stat. & $V I F$ & Coeff. & $t$-stat. & $V I F$ \\
\hline INTERCEPT & + & 2945.96 & $9.40^{* * *}$ & $\sim$ & 3009.49 & $9.69 * * *$ & $\sim$ \\
\hline \multicolumn{8}{|l|}{ Credit Criteria } \\
\hline$\underline{L T V}$ & + & & & & & & \\
\hline \multicolumn{8}{|l|}{ MaxLTV95 } \\
\hline MaxLTV90 & - & 106.45 & $3.57 * * *$ & 1.35 & 100.63 & $3.41 * * *$ & 1.35 \\
\hline MaxLTV85 & - & -170.17 & $-2.59 * * *$ & 1.48 & -203.66 & $-3.14 * * *$ & 1.46 \\
\hline MISLTV & ? & -1827.45 & $-5.71 * * *$ & 1.36 & -1746.25 & $-5.51 * * *$ & 1.35 \\
\hline Loan Size & + & & & & & & \\
\hline \multicolumn{8}{|l|}{ MaxNo } \\
\hline MaxLoan200 & - & -150.05 & $-1.98 *$ & 1.20 & -138.16 & $-1.84 *$ & 1.20 \\
\hline MaxLoan100 & - & -190.58 & $-5.78 * * *$ & 1.53 & -178.72 & $-5.48 * * *$ & 1.53 \\
\hline MaxLoan50 & - & -344.70 & $-7.86 * * *$ & 1.39 & -345.86 & $-7.97 * * *$ & 1.39 \\
\hline \multicolumn{8}{|l|}{ Market Conditions } \\
\hline$G F C$ & + & 738.28 & $4.48 * * *$ & 1.24 & 813.63 & $5.01 * * *$ & 1.23 \\
\hline MKTBLTY & - & -427.62 & $-4.25 * * *$ & 1.45 & -412.35 & $-4.14 * * *$ & 1.45 \\
\hline$Y L D C U V$ & ? & 158.17 & $4.06^{* * *}$ & 1.71 & 149.52 & $3.89 * * *$ & 1.71 \\
\hline Feature and Term & + & & & & & & \\
\hline OFFSET & + & 741.34 & $24.11 * * *$ & 1.64 & 716.98 & $23.50 * * *$ & 1.64 \\
\hline \multicolumn{8}{|l|}{ Term 26} \\
\hline TERM28 & + & 579.90 & $7.86^{* * *}$ & 1.20 & 581.22 & $7.96 * * *$ & 1.20 \\
\hline TERM30 & + & 235.60 & $9.04 * * *$ & 1.19 & 240.97 & $9.33 * * *$ & 1.20 \\
\hline \multicolumn{8}{|l|}{ Interest Rate } \\
\hline RATE & - & -129.71 & $-6.18 * * *$ & 1.41 & -129.00 & $-6.21 * * *$ & 1.40 \\
\hline \multicolumn{8}{|l|}{ Lender Type } \\
\hline LENDER & + & $\sim$ & $\sim$ & $\sim$ & 929.34 & $30.27 * * *$ & 1.69 \\
\hline \multicolumn{8}{|l|}{ Market Competition } \\
\hline MSHARE & + & 1271.91 & $28.46 * * *$ & 1.71 & $\sim$ & $\sim$ & $\sim$ \\
\hline No.obs & & & 4616 & & & 4616 & \\
\hline $\operatorname{Adj} . R^{2}$ & & & 0.49 & & & 0.50 & \\
\hline$F$-Statistic & & & 307.84 & & & 320.34 & \\
\hline$p$-value & & & 0.00 & & & 0.00 & \\
\hline
\end{tabular}

Notes: $* * * * *$ and $*$ denote the 1,5 and 10 levels of siginifcance respectively.

$$
\begin{aligned}
& \text { TFEES }_{i}=\alpha_{0}+\alpha_{1} \text { GFC }_{i}+\alpha_{2} \text { MaxLTV95 }_{i}+\alpha_{3} \text { MaxLTV90 }_{i}+\alpha_{4} \text { MaxLTV85 }_{i} \\
& +\alpha_{5} \text { MaxLoan200 }_{i}+\alpha_{6} \text { MaxLoan100 }_{i}+\alpha_{7} \text { MaxLoan50 }_{i}+\alpha_{8} \text { MaxNo }_{i} \\
& +\alpha_{9} \text { MISLTV }_{i}+\alpha_{10} \text { MKTBLTY }_{i}+\alpha_{11} \text { YLDCUV }_{i}+\alpha_{12} \text { OFFSET }_{i}
\end{aligned}
$$

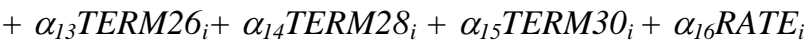

$$
\begin{aligned}
& +\alpha_{17} \operatorname{MSHARE}_{i}+e_{i} \\
& \text { TFEES }_{i}=\alpha_{0}+\alpha_{1} \text { GFC }_{i}+\alpha_{2} \text { MaxLTV95 }_{i}+\alpha_{3} \text { MaxLTV90 }_{i}+\alpha_{4} \text { MaxLTV85 }_{i}
\end{aligned}
$$

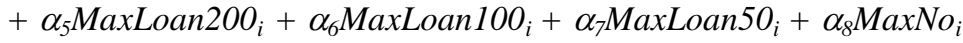

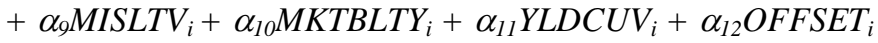

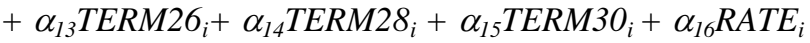

$$
\begin{aligned}
& +{ }_{I} \alpha_{17} L E N D E R+e_{i}
\end{aligned}
$$

Equation 1 is the generic equation which is estimated using Equations $1 \mathrm{a}$ and $1 \mathrm{~b}$ in order to overcome the high multicollinearity between the two independent variables MSHARE and LENDER. See Table 1 for a definition of each of the variables. 
Table 3

Regression estimate on ongoing service fees for all lenders

\begin{tabular}{|c|c|c|c|c|c|c|c|}
\hline \multirow[b]{2}{*}{ Variables } & \multicolumn{2}{|c|}{ Equation 2a } & \multicolumn{3}{|c|}{ Equation $2 b$} & \multirow[b]{2}{*}{$t$-stat. } & \multirow[b]{2}{*}{$V I F$} \\
\hline & Sign & Coeff. & $t$-stat. & VIF & Coeff. & & \\
\hline INTERCEPT & + & 1215.95 & $4.81 * * *$ & $\sim$ & 1299.79 & $5.19 * * *$ & $\sim$ \\
\hline \multicolumn{8}{|l|}{ Credit Criteria } \\
\hline$\underline{L T V}$ & + & & & & & & \\
\hline \multicolumn{8}{|l|}{ MaxLTV95 } \\
\hline MaxLTV90 & - & 128.06 & $4.56 * * *$ & 1.33 & 121.62 & $4.38 * * *$ & 1.33 \\
\hline MaxLTV85 & - & -297.06 & $-4.81 * * *$ & 1.45 & -332.90 & $-5.46 * * *$ & 1.43 \\
\hline MISLTV & ? & -1528.51 & $-5.041 * * *$ & 1.35 & -1443.46 & $-4.81 * * *$ & 1.35 \\
\hline Loan Size & + & & & & & & \\
\hline \multicolumn{8}{|l|}{$\operatorname{MaxNo}$} \\
\hline MaxLoan200 & - & -211.06 & $-2.94 * * *$ & 1.19 & -200.37 & $-2.82 * * *$ & 1.19 \\
\hline MaxLoan100 & - & -204.64 & $-6.54 * * *$ & 1.53 & -194.26 & $-6.27 * * *$ & 1.52 \\
\hline MaxLoan50 & - & -288.58 & $-6.92 * * *$ & 1.39 & -291.62 & $-7.07 * * *$ & 1.39 \\
\hline \multicolumn{8}{|l|}{ Market Condition } \\
\hline$G F C$ & + & 929.61 & $5.95 * * *$ & 1.24 & 1014.64 & $6.59 * * *$ & 1.23 \\
\hline$M K T B L T Y$ & - & -692.81 & $-7.27 * * *$ & 1.45 & -669.66 & $-8.00 * * *$ & 1.44 \\
\hline$Y L D C U V$ & $?$ & -2.59 & -0.08 & 1.35 & -10.35 & -0.32 & 1.35 \\
\hline \multicolumn{8}{|l|}{ Feature and Term } \\
\hline OFFSET & + & 696.19 & $23.96 * * *$ & 1.62 & 674.76 & $23.43 * * *$ & 1.62 \\
\hline \multicolumn{8}{|l|}{ Term26 } \\
\hline TERM 28 & + & 439.26 & $6.28 * * *$ & 1.19 & 439.84 & $6.36^{* * *}$ & 1.19 \\
\hline TERM30 & + & 217.78 & $8.79 * * *$ & 1.20 & 223.20 & $9.10 * * *$ & 1.20 \\
\hline \multicolumn{8}{|l|}{ Origination Fee } \\
\hline ORGFEE & - & 0.19 & $3.77 * * *$ & 1.04 & 0.17 & $3.44 * * *$ & 1.04 \\
\hline \multicolumn{8}{|l|}{ Lender Type } \\
\hline LENDER & + & $\sim$ & $\sim$ & $\sim$ & 973.54 & $33.70 * * *$ & 1.66 \\
\hline \multicolumn{8}{|l|}{ Market Competition } \\
\hline MSHARE & + & 1344.41 & $31.98 * * *$ & 1.68 & $\sim$ & $\sim$ & $\sim$ \\
\hline No.obs & & & 4616 & & & 4616 & \\
\hline $\operatorname{Adj} . R^{2}$ & & & 0.52 & & & 0.53 & \\
\hline$F$-Statistic & & & 360.16 & & & 374.03 & \\
\hline$p$-value & & & 0.00 & & & 0.00 & \\
\hline
\end{tabular}

Notes: $* * * * *$ and $*$ denote the 1,5 and 10 levels of siginifcance respectively.

$$
\begin{aligned}
& \text { ONGOFEE }_{i}=\beta_{0}+\beta_{1} \text { GFC }_{i}+\beta_{2} \text { MaxLTV95 }_{i}+\beta_{3} \text { MaxLTV90 }_{i}+\beta_{4} \text { MaxLTV85 }_{i}
\end{aligned}
$$

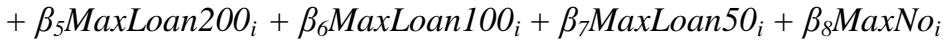

$$
\begin{aligned}
& +\beta_{9} \text { MISLTV }_{i}+\beta_{10} \text { MKTBLTY }_{i}+\beta_{11} \text { YLDCUV }_{i}+\beta_{12} \text { OFFSET }_{i}
\end{aligned}
$$

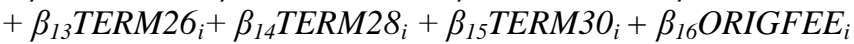

$$
\begin{aligned}
& +\beta_{17} \text { MSHARE }_{i}+e_{i} \\
& \text { ONGOFEE }_{i}=\beta_{0}+\beta_{1} \text { GFC }_{i}+\beta_{2} \text { MaxLTV95 }_{i}+\beta_{3} \text { MaxLTV90 }_{i}+\beta_{4} \text { MaxLTV85 }_{i}
\end{aligned}
$$

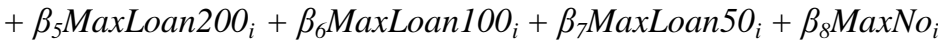

$$
\begin{aligned}
& +\beta_{9} \text { MISLTV }_{i}+\beta_{10} \text { MKTBLTY }_{i}+\beta_{11} \text { YLDCUV }_{i}+\beta_{12} \text { OFFSET }_{i}
\end{aligned}
$$

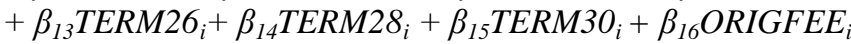

$$
\begin{aligned}
& +\beta_{17} L E N D E R_{i}+e_{i}
\end{aligned}
$$

Equation 2 is the generic equation which is estimated using Equations $2 \mathrm{a}$ and $2 \mathrm{~b}$ in order to overcome the high multicollinearity between two the two independent variables MSHARE and LENDER. See Table 1 for a definition of each of the variables. 
Table 4

Regression estimate on origination fees of mortgages for all lenders

\begin{tabular}{|c|c|c|c|c|c|c|c|}
\hline \multirow[b]{2}{*}{ Variables } & \multirow{2}{*}{$\begin{array}{c}\text { Expect. } \\
\text { Sign }\end{array}$} & \multicolumn{3}{|c|}{ Equation $3 \mathrm{a}$} & \multicolumn{3}{|c|}{ Equation $3 b$} \\
\hline & & Coeff. & $t$-stat. & $V I F$ & Coeff. & $t$-stat. & $V I F$ \\
\hline INTERCEPT & + & 559.48 & $7.67 * * *$ & $\sim$ & 556.46 & $7.61 * * *$ & $\sim$ \\
\hline \multicolumn{8}{|l|}{ Credit Criteria } \\
\hline$\underline{L T V}$ & + & & & & & & \\
\hline \multicolumn{8}{|l|}{$\bar{M} a x L T V 95$} \\
\hline MaxLTV90 & - & 4.77 & 0.585 & 1.34 & 5.70 & 0.70 & 1.33 \\
\hline MaxLTV85 & - & 75.86 & $4.26 * * *$ & 1.45 & 80.61 & $4.5 * * *$ & 1.44 \\
\hline MISLTV & $?$ & -136.82 & -1.55 & 1.35 & -148.49 & -1.67 & 1.35 \\
\hline Loan Size & + & & & & & & \\
\hline \multicolumn{8}{|l|}{$\operatorname{MaxNo}$} \\
\hline MaxLoan200 & - & 35.64 & $1.71 *$ & 1.20 & 38.01 & $1.82 *$ & 1.20 \\
\hline MaxLoan100 & - & 14.99 & 1.65 & 1.54 & 17.03 & $1.87 *$ & 1.54 \\
\hline MaxLoan50 & - & -36.71 & $-3.03 * * *$ & 1.40 & -35.67 & $-2.94 * * *$ & 1.40 \\
\hline \multicolumn{8}{|l|}{ Market Condition } \\
\hline$G F C$ & + & -113.27 & $-2.49 * *$ & 1.25 & -127.30 & $-2.81 * *$ & 1.24 \\
\hline$M K T B L T Y$ & - & 208.72 & $7.55 * * *$ & 1.44 & 202.97 & $7.34 * * *$ & 1.44 \\
\hline$Y L D C U V$ & $?$ & 46.40 & $4.89 * * *$ & 1.34 & 47.13 & $4.96 * * *$ & 1.34 \\
\hline Feature and Term & + & & & & & & \\
\hline OFFSET & + & 10.43 & 1.17 & 1.82 & 7.94 & 0.89 & 1.82 \\
\hline \multicolumn{8}{|l|}{ Term 26} \\
\hline TERM28 & + & 79.82 & $3.93 * * *$ & 1.20 & 83.82 & $4.13 * * *$ & 1.20 \\
\hline TERM30 & + & 7.97 & 1.10 & 1.22 & 8.51 & 1.17 & 1.22 \\
\hline \multicolumn{8}{|l|}{ Ongoing Fee } \\
\hline ONGOFEE & - & 0.02 & $3.77 * * *$ & 2.10 & 0.02 & $3.43 * * *$ & 2.14 \\
\hline \multicolumn{8}{|l|}{ Lender Type } \\
\hline LENDER & + & $\sim$ & $\sim$ & $\sim$ & -52.58 & $-5.58 * * *$ & 2.06 \\
\hline \multicolumn{8}{|l|}{ Market Competition } \\
\hline MSHARE & + & -88.13 & $-6.57 * * *$ & 2.04 & $\sim$ & $\sim$ & $\sim$ \\
\hline No.obs & & & 4616 & & & 4616 & \\
\hline $\operatorname{Adj} . R^{2}$ & & & 0.04 & & & 0.04 & \\
\hline$F$-Statistic & & & 14.37 & & & 13.48 & \\
\hline$p$-value & & & 0.00 & & & 0.00 & \\
\hline
\end{tabular}

Notes: $* * * * *$ and $*$ denote the 1,5 and 10 levels of siginifcance respectively.

$$
\begin{aligned}
& \text { ORIGFEE } E_{i}=\lambda_{0}+\lambda_{1} \text { GFC }_{i}+\lambda_{2} \text { MaxLTV95 }_{i}+\lambda_{3} \text { MaxLTV90 }_{i}+\lambda_{4}{\text { MaxLTV } 85_{i}} \\
& +\lambda_{5} \text { MaxLoan200 }_{i}+\lambda_{6} \text { MaxLoan100 }_{i}+\lambda_{7} \text { MaxLoan50 }_{i}+\lambda_{8} \text { MaxNo }_{i} \\
& +\lambda_{9} \text { MISLTV }_{i}+\lambda_{10} \text { MKTBLTY }_{i}+\lambda_{11} \text { YLDCUV }_{i}+\lambda_{12} \text { OFFSET }_{i}
\end{aligned}
$$

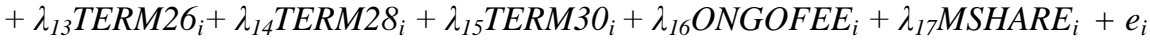

$$
\begin{aligned}
& \text { ORIGFEE } E_{i}=\lambda_{0}+\lambda_{1} G F C_{i}+\lambda_{2} \text { MAXLTV95 }+\lambda_{3} \text { MAXLTV90 }+\lambda_{4} \text { MAXLTV85 }_{i} \\
& +\lambda_{5} \text { MAXLoan200 }_{i}+\lambda_{6} \text { MAXLoan100 }_{i}+\lambda_{7} \text { MAXLoan50 } i+\lambda_{8} \text { MAXNO }_{i} \\
& +\lambda_{9} \text { MISLTV }_{i}+\lambda_{10} \text { MKTBLTY }_{i}+\lambda_{11} \text { YLDCUV }_{i}+\lambda_{12} \text { OFFSET }_{i}
\end{aligned}
$$

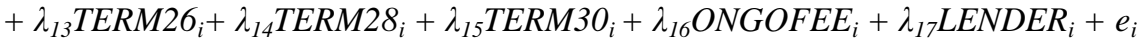

Equation 3 is the generic equation which is estimated using Equations $3 \mathrm{a}$ and $3 \mathrm{~b}$ in order to overcome the high multicollinearity between two the two independent variables MSHARE and LENDER. See Table 1 for a definition of each of the variables. 
Table 5

Summary of key findings

\section{Research Questions}

Are there fee differentials (total fees, ongoing service fees and origination fees) across the two types of mortgage lenders?

Do differences in lender credit criteria impact on fee levels (total fees, ongoing service fees and origination fees)?

Do the GFC and mortgage market liquidity also affect the three types of fees?

Does the trade-off relationship between interest rates and total mortgage fees in adjustable rate mortgages (ARMS) during the research period exist?

Does market competition affect the fees?

Are fees related to the loan features?

\section{Key Findings}

Yes. Banks charge more total fees and ongoing service fees than mortgage corporations but they require slightly lower origination fees.

Yes. Total fees and ongoing service fees are positively related to maximum loans and maximum LTV. However, origination fees have the opposite relationship with the latter variables.

Yes. The GFC positively while market liquidity negatively affects total fees and ongoing service fees. However, origination fees have the opposite relationship with the GFC and market liquidity.

Yes. A negative relation between total fees and interest rates is found.

Yes. Market share is positively related with total and ongoing fees but negatively related with origination fees.

Yes. Loans with an offset account facility and longer term are associated with higher total, ongoing and origination fees. 